\title{
E-Portfolio Reflective Learning Strategies to Enhance Research Skills, Analytical Ability, Creativity and Problem-Solving
}

\author{
Syamsul Nor Azlan Mohamad ${ }^{1}$, Mohamed Amin Embi ${ }^{2} \&$ Norazah Mohd Nordin ${ }^{2}$ \\ ${ }^{1}$ Universiti Teknologi MARA, Malaysia \\ ${ }^{2}$ Universiti Kebangsaan Malaysia, Malaysia \\ Correspondence: Syamsul Nor Azlan Mohamad, Universiti Teknologi MARA, Malaysia. E-mail: \\ snazlan@siswa.ukm.edu.my
}

Received: August 11, 2016

Accepted: August 29, 2016

Online Published: September 19, 2016

doi:10.5539/ass.v12n10p228

URL: http://dx.doi.org/10.5539/ass.v12n10p228

\begin{abstract}
This paper presents the effect on reflective learning strategies towards the implementation of e-Portfolio to enhance learner higher order thinking skills. The purpose of the study was to examine the learner's higher order thinking skills that focus on four factors which is research skills, analytical ability, creativity and problem-solving after the implementation of e-Portfolio in their learning. Initially, this paper was conducted a study with a total number of twenty-four students as a small group evaluation. The qualitative analysis was explored four factors which involved (1) research skills (2) analytical ability (3) creativity and (4) problem-solving to investigate the practicality of e-Portfolio in reflecting their learning. The findings were reported that learners reflective learning has a significant effect to create a self-confident, self-directed and retain their motivation at higher level. Reflective learning strategies will enforce the learner in gaining their interest in learning. The integration of e-Portfolio and reflective learning strategies will create an opportunity to enhance higher order thinking skills in teaching and learning for higher education environment.
\end{abstract}

Keywords: e-portfolio, reflective learning, reflection, learning strategy

\section{Introduction}

It needs to be accentuated that learning e-Portfolio is not solely dependent on a set of objectives which are justified by an agreement but also dependent on practices that engage learners reflect on their actions during the art-making process. Subsequently, e-Portfolio is most beneficial in fostering active learning, enabling dialogues, encouraging cooperation between learners and instructors, providing valid and authentic assessment tasks that are related to the art and humanities curriculum, and imparting respect of the voices and personal styles in individuals (Torres Pereira de Eca, 2005).

It is worth highlighting that e-Portfolio should be designed to link learners' higher order thinking skills with exchange of reflection of ideas and feedbacks (Lorenzo \& Ittleson, 2005). Additionally, to ensure that the application of e-Portfolio is a success, learners are able to get immediate and regular feedbacks throughout the process of constructing their portfolios (Ahn, 2004). After all, various researchers have agreed that learning is a process and the intent is to enhance learners' respective performances (Rosenberg, 2007; Ritzhaupt, Singh, Dedrick, Hogarty, \& Seyferth, 2006; Azlan, 2015a).

Dewey (1933) was the pioneer who proposed the concept of reflection which is defined as a repeated thinking and searching to understand the causal effects and stimulate deeper thinking. Reflection is a metacognitive skill that helps learners to be aware of their mental structures and form the meaning form experience, which contributes to reorganizing and restructuring contexts (Ertmer \& Newby 1996; Korthagen, 2001). Prior to that, reflection enables students to gain knowledge to become refined and differentiated gradually.

Nicole Buzzetto-More (2010); Paulson and Paulson (1994) mentioned no form of e-learning is more constructivist than e-Portfolio referring to its potential as workspace and showcase of students reflection in constructing their meaning and experiences. In other words, E-Portfolio stimulates self-reflecting by collecting evidence of learning (Azlan, 2015c; Van Tartwijk \& Driessen, 2009). By utilizing reflective learning, learners are able to evaluate and diagnose their own learning (Ertmer \& Newby, 1996). Challis (2005) stated that the prerequisite of using e-Portfolio is to make sure reflection becomes the driving factor for learning. 
In contrast, Kocoglu (2008) as cited by Ferial Mohammad Awwad (2013) in his study of Turkish students' perceptions on the role of e-Portfolios in their professional development found that the e-Portfolio provided opportunities for them to work collaboratively and scaffold their ongoing professional development. However, the teachers in training of this study did not believe that reflection is important in e-Portfolio. Nevertheless, NoHrisos, Illing and Burford (2008) revealed that e-Portfolio is valuable to promote reflection among students at the foundation level in a university.

Several questions and concerns need to be considered when new and improved forms of organizing for learning such as in the introduction of e-Portfolio. Such concerns may include considering the implications in curriculum and assessment. Next, it needs to be looked into whether learners would take a more active role in organizing the content and tasks once they are able to engage in learning while being on the move. Subsequently, it needs to be identified how learners will perform in such situation and the following consequences. Another significant concern to consider would be the responses from both learners and institutions to the move of learning through spaces beyond their immediate control. When such situation subsist, educators would need to cogitate on the appropriate methods to diligently monitor students' activities.

\section{Literature Review}

Researchers have been arguing on the importance of offering students feedback that is timely and interactive so that students' misconceptions and difficulties can be identified through frequent interactions and their strategies of tackling tasks can be continuously improved (Clark, 2012; Eynon, 2012). The e-Portfolio system allows students to share e-Portfolios via hyperlinks and obtain facilitators' and peers' feedback with relative ease (Heinrich, 2007). By combining online and face-to-face feedback interactions, teachers can flexibly use both teacher guidance as well as students' contributions to productive learning. Nicol, Thomson and Breslin (2014) have supported that peer-feedback in particular can be employed as an approach to peer-learning, which strengthens learners' cognitive processes as they make critical judgments of peers' e-Portfolios against assessment standards (Nicol et al., 2014). Due to that, Rees (2005) proposes that reflection has to become a mandatory element in e-Portfolio which leads the students towards learning; otherwise, they may become passive. There are some attributes gained from reflective or reflection activity. These attributes are described in the following paragraphs.

a. Deep Learning: The previous researcher Astin (1984), as cited by Hunt (2003), argued that deep learning process involves the quality and quantity of learners' cognitive involvement and retention during the activities. He believes that by encouraging learners, cooperation among students, active learning, prompt feedback, time on task, high expectations for students as well as demonstrating respect for the diverse talents and learning styles contribute to deep learning. Bird, Bowell, Case, Friesen et al. (2004) defined deep learning as a development of conditioned knowledge and metacognitive through inquiry based activity. The context of deep learning, unlike in classrooms, is not the place to transmit information but rather to provoke dissent, nurture rapport and collegiality and light the fires of curiosity and the passion for inquiry. Deep learning is an authentic learning experience between facilitator and learners, where both fully communicate and engage to meet the objective and solve the problem via e-Portfolio.

b. Reasoning Techniques: Parkes, Dredger (2013) conducted a study on reflective practice using e-Portfolio to facilitate learning. They found that e-Portfolio is a network space to defend and present the case by engaging reasoning to deliberate on the theory, context and practice. Reasoning requires higher order thinking skills when reflecting with a variety of media and by questioning and reasoning, learners are able to increase their thinking skills and learn more.

c. Ownership: The concept of ownership is an important component to facilitate students' active engagement and harness their enthusiasm and creativity (Garrett, 2011). However, Lorenzo and Ittleson (2005) have noted some of the ownership issues such as copyright and privacy, complexity and scope, and questions about how to properly scaffold the portfolio development process to encourage reflection. The power of ownership is a driven factor for the learners to feel the sense of belonging and responsibility toward their own learning. Therefore, Cameron and Anderson (2006) suggested that ownership should be linked to social presence. Hence, the e-Portfolio system with social presence allows users to communicate and create the sense of ownership which considered to be crucial in constructivism, where learners are expected to learn in their own unique way.

Researchers such as (Hussain, 2011; Paris \& Ayres, 1994) suggested that implementing e-Portfolio could effectively induce reflective learning. The e-Portfolio integrate with reflective learning creates impulsive constructivism environment that makes learning intentional and deliberate. Reflective learning is a process of authentic problem solving, critical and constructive which promotes autonomous learning that aims to develop 
learners' higher order thinking skills. The creation of e-Portfolio is a continuous process and reflection allows learners to focus on the learning objectives (Jaw-Kuen, 2012; Liu \& Lin, 2010). In e-Portfolio, performing reflection is the way to evaluate their own learning through observing and emulating each other. Therefore, reflective approaches are more effective and directional to the learners.

\section{Methodology}

Prior to the study, the one group involves 24 participants was briefed on the implementation of the e-Portfolio with a specific role and task. The chosen participants for this implementation phase were students from Bachelor of Education (Hons) Art \& Design, Faculty of Education in which 24 students and 1 facilitator would be involved in this procedure. The determination of sampling size in the formative evaluation of small group and field user testing sessions was done based on (Tessmer, 1993) who has mentioned the usability of less than 20 participants in small group evaluation and between 20 and 30 participants for field test evaluation.

\section{Data Analysis}

Data analysis was collected based on daily tracking and monitoring through the system. Data collected in the earlier stage of the implementation comprised of observational and system generated data. This findings showed a weekly pattern of learner's reflection and participation which includes hint, prompt and feedback activity. Then thematic analysis (Azlan, 2017) was executed to determine and retrieved a listed verbatim or statements made by the participants on their experiences.

For this session, the e-Portfolio would go through about nine weeks or at least complete one unit for the whole syllabus. This also served as an active engagement for the learners and encouraged them to participate in activity. Figure 1 displays the diagrammatic representation of hand-ons activity. One course would be selected and implemented in this prototype. The selected course is ADE520 - Typography and Page Composition with 3 credit hours. Ideally, this course is a project-based subject which requires students to use a set of skills based on the course outcomes stated in the syllabus. This subject is a core subject and is compulsory for the students. As part of the syllabus, formative assessment including assignments and projects are evidence-based as proof of the students' progress in the classroom.

Below are the diagrammatic representation of task sequences and learning output:

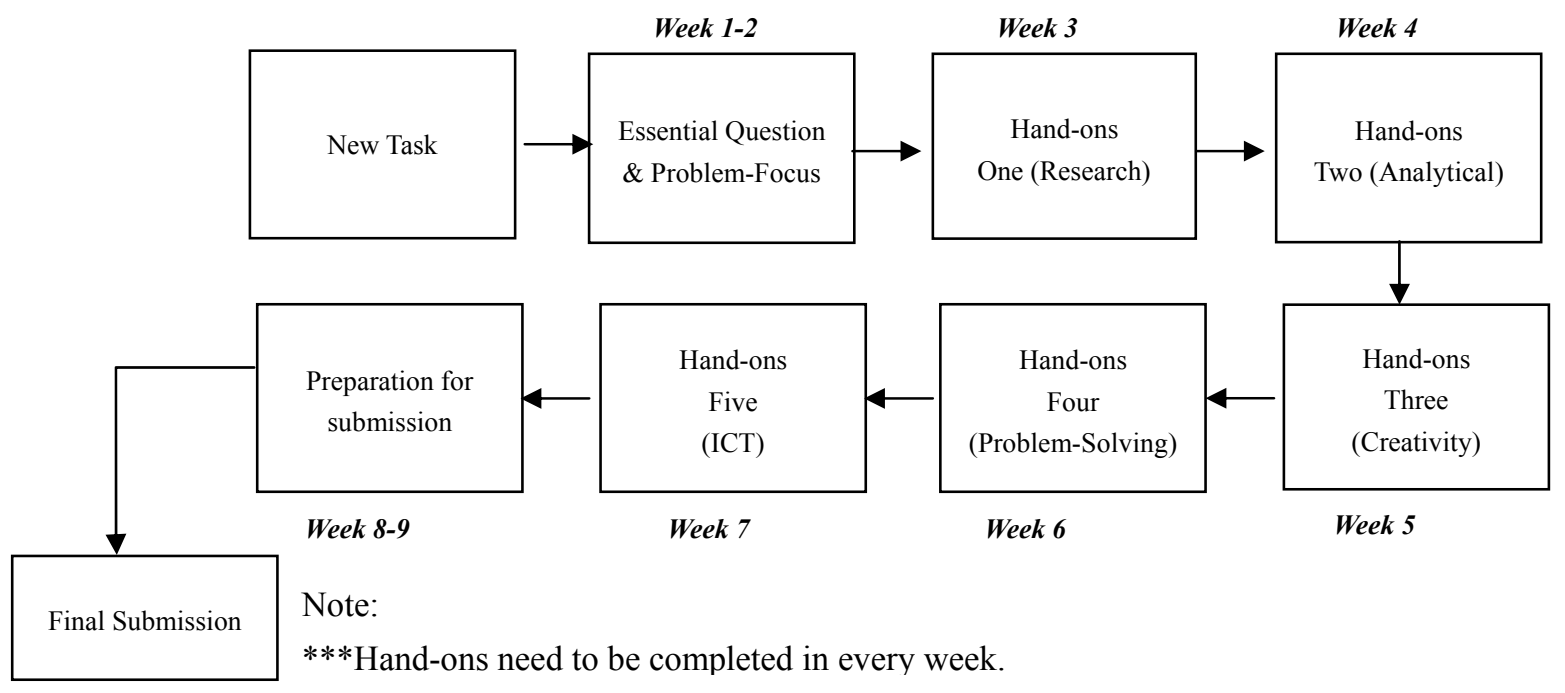

Figure 1. Diagrammatic representation of hand-ons acitivity

Below are the designated questions based on the Project-based Pedagogical Framework by (Azlan, 2015b).

Table 1. Task sequences and learning output according to Project-based Pedagogical Framework

\begin{tabular}{ll}
\hline Task Sequences & Learning Output \\
\hline Essential Question & What makes your magazine layout is look more creative than to other? \\
Problem-Focussed & How to create and produce a creative and good magazine layout based on the theme given? \\
Researching & What is layout and page composition? \\
\hline
\end{tabular}




\begin{tabular}{ll}
\hline Analytical & What are the design principles use in designing layout and page composition? \\
Creativity & State the concept of idea of your layout and page composition? \\
Problem Solving & Discuss the creative tools using in creating layout and page composition? \\
ICT & Discuss the use of media infused in the layout and page composition?
\end{tabular}

This findings showed a weekly pattern of learner's reflection and participation which includes hint, prompt and feedback activity.

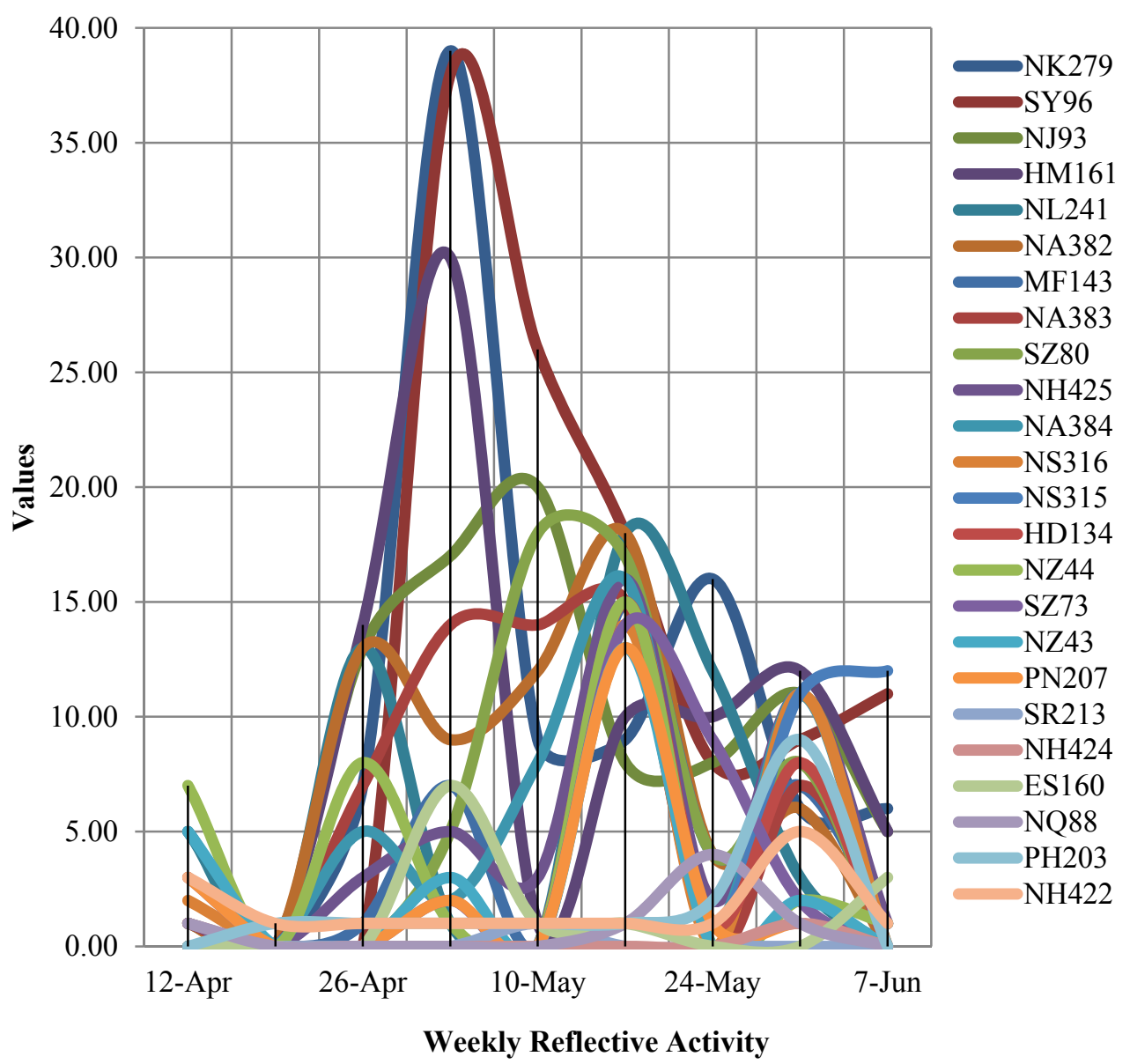

Figure 2. Weekly Reflection

To begin with, the facilitator posted questions that needed to be solved, answered and shared. Usually, the facilitator would post one or two questions per week continuously for six weeks. The facilitator named the session as "Thursday to Share and Reflect (TSR)".

In addition, the values showed points gained by the learners for every reflection on the questions. The reflection involved peers and facilitators to solve the problem given. This data showed two weeks of training session, six weeks of e-Portfolio learning process and one week for submission and assessment. Here are the findings which represent a learner's participation in the reflection sessions. The framing question consists;

As start session, the researcher provided participant with an analytical question to test their analytical skills. The question prompt "What are the design principles use in designing layout and page composition?". There are many answer was given such;

There a number of participants also shared and posted their thought on related topic. However, the tendency of repetition the same answer is very high due to the first time engage with e-Portfolio. The researcher and subject matter expert realize that more collaboration and interaction is needed to increase learner self-esteem and 
motivate them to reflect based on their own understanding.

\begin{tabular}{ll}
\hline Student & Verbatim \\
\hline @PN207: & Composition is the manner pieces or components are combined and arranged visually to tell a \\
& story. Proper composition considers alignment, grouping, placement, space, and visual flow \\
& within a layout. This layout can be any medium. Once a proper audience and purpose have \\
& been determined then composition, components, and concept can encompass that identified \\
& purpose allowing a successful design. \\
& The answer was given based of her understanding about the related question. This student \\
& makes an effort to synthesize the information rather than of coping directly from the net. \\
& Referring to @MF143 used to simplified the answer provided with a hyperlinks as a references \\
& that might be useful to their peers. \\
& In my opinion, the main principle and element that related to designing layout and page \\
& composition is balance and space. We might think to put all information in one composition and \\
& layout is good, but we forgot that less is always more
\end{tabular}

The second question tested learner creativity skills, the question is "State the concept of idea of your layout and page composition?". Purposely, this question was designed to express learner idea and concept of the project-based given. There are some sample of idea share in e-Portfolio;

\begin{tabular}{ll}
\hline Student & Verbatim \\
\hline @PH203: & $\begin{array}{l}\text { for my final magazine I choose street art which is wheat paste. Wheat paste also known as flour } \\
\text { paste, or simply paste is a gel or liquid adhesive made from wheat flour or starch and water. It } \\
\text { has been used since antiquity for various arts and crafts such as book binding, collage, and } \\
\text { adhering paper posters and notices to walls. Closely resembling wallpaper paste, a crude wheat } \\
\text { flour paste can be made by mixing roughly equal portions of flour and water and heating until } \\
\text { the mixture thickens }\end{array}$ \\
\hline
\end{tabular}

At this level, learner gave their justification and to ensure that the idea is relevant by supporting with evidence-based. The feedback from facilitator and peers will help the learner to find strength, weakness and opportunity to improve the idea.

\begin{tabular}{ll}
\hline Student & Verbatim \\
\hline @HM616: & After doing some research, I have decided to do "mural" art that's in the street categories. \\
& Mural is a huge work, often on a legal wall. It might be done by an individual, an informal \\
& group, or a crew. A mural might depict a single scene, or it might be a series of standalone or \\
& loosely connected images or characters. The strength of this art is about love, peace and \\
& educate. Simple image but yet give a bigger impact. The only weakness its only a lots of patient, \\
& time costing and detailed. The threats of this mural sometimes could get in vandalism activity if \\
& we don't follow the right procedure.
\end{tabular}

@NA383: Its sound good. wish you luck...

@SA266: As I read your post... Environment art is actually applied in our daily life. Narrow down your interest by using SWOT analysis. The brief ideas of your own is a 1st step... but it's still broad, now your task is to narrow down the theme according to your target audience, interest etc.

@HM616: $\quad$ Thanks, will take note...

Thus, the facilitator act as guidance to help the learner to be more self-directed in finding the solution. The solution was driven by the experience of collecting, sharing and reflecting among their colleagues. The reflection is the best mechanism to ensure the learner actively engage with situation and produce the best quality of work 
Questions is not only content-based, but also technical-based question. This question urged the learner to find the best practices to solve the problem. The question is "Discuss the creative tools using in creating layout and page composition? Hint: What are the tool involved in making your layout? Justify why you choose that tool and share your experience.

\begin{tabular}{|c|c|}
\hline Student & Verbatim \\
\hline @NH424: & $\begin{array}{l}\text { for me I prefer using adobe illustration it is because it is easily to handle and it also easy to make } \\
\text { word composition and picture }\end{array}$ \\
\hline @HD134: & wow, same goes with me.. :) \\
\hline @NH424: & $\begin{array}{l}\text { Ooghh really?. Actually } i \text { do not explore any more by using adobe InDesign. By the way adobe } \\
\text { InDesign is nice and interesting... hope I can learn more about that...:D }\end{array}$ \\
\hline @PH203: & Me too..I hope I can explore InDesign. \\
\hline @SY96: & $\begin{array}{l}\text { For me there are two tools that I will use that is: } \\
\text { a) Adobe Photoshop - it help me to edit a picture before put it in my layout. b) Adobe InDesign-as } \\
\text { we know we use it in class to do our own magazine layout and it is easy if we practice to use it. }\end{array}$ \\
\hline @MF143: & $\begin{array}{l}\text { I agree with@SY96. I prefer Adobe InDesign and Photoshop in making layout and page } \\
\text { composition. InDesign helps in arranging your layout and composition. Adobe Photoshop help us } \\
\text { to make picture look better. Here is a sample of layout composition } \\
\text { https://www.youtube.com/watch?v=WNVPbsGMf8 }\end{array}$ \\
\hline
\end{tabular}

This conversation highlighted their prior experience, expectation and assumption to solve the problem. It' based on individual real-task experience comprehend certain technical parts in their learning. The experience is individual and unique, it could the same or different. Problem-solving anticipated a strong relationship in which learners take ownership through student-directedness by engaging with hands-on activities. The learner should responsible to enhance their potential as a great thinker and problem-solver. The social interaction in e-Portfolio is medium to the learner expose themselves and learn more from others.

\section{Findings and Discussions}

Based on the findings, the researcher has identified three factors which benefits learners using the e-Portfolio.

Recognition and Awards. According to Murat (2010), motivation is the fuel to energize relatedness, autonomy and competence. Similarly, Bohlin, Milheim and Viechnicki (1990) with Keller (2010), they indicated that the recognition and awards are the best reinforcement to intensify self-confidence in the effort of fulfilling and accomplishing learning. The findings found that e-Portfolio highlighted a recognition and awards as one of the strategies to retain motivation at a high level. The recognition and awards allow them to work on the task and achieve certain points to ensure that they complete it.

Reflective Learning. Reflective learning is the core of e-Portfolio. Reflection offers learners frequent interaction and their approach to solve problems. It is significant with Lim (2004) mentioned, reflection is intended to encourage learners be active which would trigger their self-directedness to engage with the activities. Based on the findings, the researcher found the learners participated and contributed to the ideas and the feedback. Researchers such as Granberg (2010) with Trilling and Fadel (2009) suggested that learners need to equip and prepare themselves in developing higher order thinking ability to enable themselves in being self-directed to deal with complex situations. Reflective learning trains learners to determine and reach the resources before the creation process; for example, preparing statements that provided valid resources, strong justifications and recommendations. It allows the learners to gain critical thinking ability to reflect on each question imposed by their facilitators or peers. The techniques of critical thinking may work by defining, summarizing and evaluating the subject, and considering the causal-effect of subjects. Hence, the learners must give clear opinion and interpret the meaning based on the findings.

Redefining the meaning of e-Portfolio. It is important for the researcher to gather the learner voices to redefine the meaning of e-Portfolio from their perspectives. According to Barrett (2006), Barrett (2007b), Le (2012), Lorenzo and Ittleson (2005), with Moores and Parks (2010), e-Portfolio exhibits its potentiality to work as a storage, workspace and showcase. The e-Portfolio also allows learners to update, edit and create their documents. The creation of evidence-based learning in digital and work format allows learners to use e-Portfolio as a 
personal workspace. Hence, the learners are able to demonstrate their projects, tasks or assignments virtually for individual presentation, institutional benchmarking, and future job hunting. The researcher believes that these contributed directly or indirectly to self-directed learning among learners. This is supported by Craven, Marsh and Burnett (2003) as well as McInerney et al. (2012) who asserted that the positioning of self-concept into self-directed learning is the way for the learners to perceive their strengths, weaknesses, abilities, attitudes and values towards the attainment and success of learning.

The objective of this study has always been, up to now, to verify whether e-Portfolio can be regarded as a valuable tool to encourage students to reconsider and narrative their learning experience by engaging that reiterative process of looking back to previous performance and looking forward to goals and by reflecting of their learning. The reflection is a process to support the learner growth and form through feedback by peers and facilitator but also the awareness makes them skilful or know as reflective practitioner. In this study, reflection apart of authentic assessment is focus on learner analytical skills, project-based skills, problem based skills and critical thinking skills that encourages a constructivist approach to learning, where students learn through application. These skills help learners to raised self-reflection, stimulated creativity, improved active learning, improving peer communication and facilitator-students' relations.

\section{References}

Ahn, J. (2004). Electronic portfolios: Blending technology, accountability and assessment. T.H.E. Journal, 31(9), $12-18$.

Barrett, H. C. (2006). Using Electronic Portfolios for Classroom Assessment.

Barrett, H. C. (2007). Researching electronic portfolios and learner engagement: The REFLECT Initiative. Journal of Adolescent \& Adult Literacy, 50(6), 436-449. http://dx.doi.org/10.1598/JAAL.50.6.2

Bird, S., Bowell, D., Case, J., \& Friesen, G. (2004). Deep learning for a digital age: Technology's untapped potential to enrich higher education. Christian Scholar's Review, 33(4), 581-583.

Bohlin, R. M., Milheim, W. D., \& Viechnicki, K. J. (1990). A model for the motivational instruction of adults. communications and technology. In Proceedings of selected paper presentations at the convention of the association for educational communications and technology (pp. 1-12).

Buzzetto-More, N. (2010). Assessing the efficacy and effectiveness of an e-portfolio used for summative assessment. Interdisciplinary Journal of E-Learning and Learning Objects, 6, 61-85. Retrieved from http://www.editlib.org/p/44774/

Cameron, D., \& Anderson, T. (2006). Comparing Weblogs to Threaded Discussion Tools in Online Educational Contexts.

Challis, D. (2005). Towards the mature e-portfolio: Some implications for higher education.

Clark, I. (2012). Formative assessment: assessment is for self-regulated learning. Educational Psychology Review, 24(2), 205-249. http://dx.doi.org/10.1007/s10648-011-9191-6

Craven, R. G., Marsh, H. W., \& Burnett, P. C. (2003). Cracking the self-concept enhance- ment conundrum: A call and blueprint for the next generation of self-concept enhancement research. In H. W. Marsh, R. G. Craven, \& D. M. McInerney (Eds.), International advances in self research (Vol. 1, pp. 91-126).

Dewey, J. (1933). How we think: A Restatementof the relation of reflective thinking to the educative process. Chicago: Henry Regnery.

Ertmer, P. A., \& Newby, T. J. (1996). No Title. Instructional Science, 24(1), 1-24. http://dx.doi.org/10.1007/ BF00156001

Eynon, J. E. C., \& B. (2012). Measuring Student Progress with E-portfolios. $A A C \& U, 6-8$.

Ferial Mohammad Awwad, M. B. N., \& N. S. S. (2013). The Impact of Electronic Portfolio on Developing Reflective Thinking and Self Directed Learning Readiness. Cypriot Journal of Educational Sciences, 8(1), 78-104.

Garrett, N. (2011). An e-portfolio Design Supporting Ownership, Social Learning, and Ease of Use. Educational Technology \& Society, 14, 187-202.

Granberg, C. (2010). E-portfolios in teacher education 2002-2009: the social construction of discourse, design and dissemination. European Journal of Teacher Education, 33(3), 309-322. http://dx.doi.org/10.1080/02619761003767882 
Heinrich, B. R. (2007). Preparation for lifelong learning using ePortfolis. European Journal of Enggineering Education, 32(6), 653-663. http://dx.doi.org/10.1080/03043790701520602

Hunt, S. K. (2003). Encouraging student involvement: An approach to teaching communication. Communication Studies, 54(2). http://dx.doi.org/10.1080/10510970309363275

Jaw-Kuen, J. M. S. (2012). The Development of Web-Based Self-Reflective Learning System for Technological Education. The Turkish Online Journal of Educational Technology, 11(1).

Keller. (2010). Motivational Design for Learning and Performance. Springer. http://dx.doi.org/10.1007/978$1-4419-1250-3$

Kocoglu, Z. (2008). Turkish EFL student teachers perceptions on the role of electronic portfolios in their professional development. The Turkish Online Journal of Educational Technology, 7(3), 71-79.

Korthagen, F. A. J. (2001). No Title. the pedagogy of realistic teacher education. Mahwah, N.J. L. Erlbaum Associates.

Le, Q. (2012). E-Portfolio for enhancing graduate research supervision. Quality Assurance in Education, 20(1), 54-65. http://dx.doi.org/10.1108/09684881211198248

Lim, B. R. (2004). Challenges and issues in designing inquiry on the Web. British Journal of Educational Technology, 35(5), 627- 643. http://dx.doi.org/10.1111/j.0007-1013.2004.00419.x

Liu, E. Z. F., \& Lin, C. H. (2010). The survey study of mathematics motivated strategies for learning questionnaire (MMSLQ) for grade 10-12 Taiwanese students. Turkish Online Journal of Educational Technology, 9(2), 221-233.

Lorenzo, G., \& Ittleson, J. (2005). Demonstrating and assessing student learning with eportfolios. EDUCAUSE-ELI Paper 3, 2005.

McInerney, D. M., Cheng, R. W. -y., Mok, M. M. C., \& Lam, A. K. H. (2012). Academic Self-Concept and Learning Strategies: Direction of Effect on Student Academic Achievement. Journal of Advanced Academics, 23(3), 249-269. http://dx.doi.org/10.1177/1932202X12451020

Moores, A., \& Parks, M. (2010). Twelve tips for introducing E-Portfolios with undergraduate students. Medical Teacher, 32(1), 46-49. http://dx.doi.org/10.3109/01421590903434151

Muhammad Athar Hussain, A. M. M. S. (2011). An Inquiry into Benefits of Reflective Practice in Open and Distance Learning. Turkish Online Journal of Distance Education, 12(2).

Murat, K. (2010). Student's Perceptions to Use Technology for Learning: Measurement Integrity of The Modified Fennema-Sherman Attitudes Scales. The Turkish Online Journal of Educational Technology, 9(1), 185-201.

Nicol, D., Thomson, A., \& Breslin, C. (2014). Rethinking feedback practices in higher education: a peer review perspective. Assessment \& Evaluation in Higher Education, 39(1), 102-122. http://dx.doi.org/10.1080/0260 2938.2013.795518

NoHrisos, S., Illing, J. C., \& Burford, B. C. (2008). Portfolio learning for foundation doctors: Early feedback on its use in the clinical workplace. Medical Education, 42, 214-223. http://dx.doi.org/10.1111/j.1365-2923. 2007.02960.x

Paris, S. G., \& Ayres, L. R. (1994). Becoming Reflective Students and Teaching. American Psychological Association.

Parkes, Dredger, H. (2013). Parkes, Dredger, and Hicks ePortfolio as Reflective Practice. International Journal of E-Portfolio, 3(2), 99-115.

Paulson, F. L., \& Paulson, P. (1994). Assessing portfolios using the constructivist paradigm. Student Portfolios.

Rees, C. (2005). The use (and abuse) of the term portfolio. Medical Education, 39, 463. http://dx.doi.org/10.1111/j.1365-2929.2005.02119.x

Ritzhaupt, A. D., Singh, O., Dedrick, R., Hogarty, K., \& Seyferth, T. (2006). ePortfolio integration in higher education: An analysis of student attitudes towards an ePortfolio Initiative. In Paper presented at the Florida Educational Research Association.

Rosenberg, M. (2007). The eLearning Guild's Hanbook of e-Learning Strategy.

Syamsul Nor Azlan, M. A. E., \& N. N. (2015a). Are Students Ready to Adopt E-Portfolio? Social Science and 
Humanities Context. Asian Social Science, 11(13), 269-275. http://dx.doi.org/10.5539/ass.v11n13p269

Syamsul Nor Azlan, M. A. E., \& N. N. (2015b). Designing Project-Based Learning ( PjBL ) Activities for Art and Design E-Portfolio Using Fuzzy Delphi Method as a Decision Making. Asian Social Science, 11(28), 45-50. http://dx.doi.org/10.5539/ass.v11n28p45

Syamsul Nor Azlan, M. A. E., \& N. N. (2015c). Determining e-Portfolio Elements in Learning Process Using Fuzzy Delphi Analysis. International Education Studies, 8(9), 171-176.

Syamsul Nor Azlan, M. A. E., \& N. N. (2017). Designing an E-Portfolio as a Storage, Workspace and Showcase for Social Sciences and Humanities in Higher Education Institutions. Asian Social Science, 12(5), 185-194.

Tessmer, M. (1993). Planning and conducting formative evaluations, improving the quality of education and training. London: Kogan Page Limited.

Torres Pereira de Eca, M. T. (2005). Using portfolios for external assessment: An experimentin Portugal. International Journal of Art \& Design Education, 24(2), 209-218. http://dx.doi.org/10.1111/j.1476-8070. 2005.00441.x

Trilling, B., \& Fadel, C. (2009). 21st century skills: Learning for life in our times. San Francisco: Jossey-Bass.

Van Tartwijk, J., \& Driessen, E. W. (2009). Portfolios for assessment and learning: AMEE Guide no. 45. Medical Teacher, 31(9), 790-801. http://dx.doi.org/10.1080/01421590903139201

\section{Copyrights}

Copyright for this article is retained by the author(s), with first publication rights granted to the journal.

This is an open-access article distributed under the terms and conditions of the Creative Commons Attribution license (http://creativecommons.org/licenses/by/4.0/). 